\title{
Effectiveness of Handoff Educational Program on Nurses Interns' Knowledge, and Communication Competence
}

\author{
Abeer Mohamed Seada, Somaya Ahmed Bayoumy \\ Department of Nursing Administration, Faculty of Nursing, Cairo University, Cairo, Egypt \\ Email address: \\ abeerseada@yahoo.com (A. M. Seada), somaya.aljazzar@gmail.com (S. A. Bayoumy) \\ To cite this article: \\ Abeer Mohamed Seada, Somaya Ahmed Bayoumy. Effectiveness of Handoff Educational Program on Nurses Interns' Knowledge, and \\ Communication Competence. American Journal of Nursing Science. Vol. 6, No. 6, 2017, pp. 467-477. doi: 10.11648/j.ajns.20170606.14
}

Received: October 27, 2017; Accepted: November 10, 2017; Published: November 24, 2017

\begin{abstract}
With the growing complexity of health care, the ability to communicate becomes essential within the health team members. Health care organization has great expectations for new graduate nurses to communicate skillfully while promoting safe patient care. Student nurses interns may lacked experiences with important communication skills and are fearful of making mistakes which may affect patient safety. One way to improve handoff communication skill among nurses interns is through education. This study was intended to examine the effectiveness of handoff educational program on nurse's interns' handoff knowledge, and communication competence. Quasi - experimental study design was utilized: The study was conducted in intensive care units which affiliated with Kaser El Ainy hospital where nurses interns were trained. Study sample composed of 30 nurses interns who were undertaking their internship year between 2016-2017. Data were collected through utilizing Handoff knowledge questionnaire that was developed by the researcher and Handoff communication competence observational checklist developed by [1] and modified by the researchers to measure hand-off communication competence of nurses interns during the process of bedside handover. Results revealed that there were statistical significant and marked improvement in nurses interns' levels of handoff knowledge dimensions as well as statistical significant differences in their mean scores of hand- off communication competence during different periods of assessment. The current study provide evidence that handoff educational program enhance nurses interns handoff communication competence. Handoff communication skills should taught formally during nursing academic education concerning the way that information is given, verified as well as all handoff communication competencies during process of patient bedside handoff. Future researches with larger sample sizes and multiple settings are recommended to substantially evaluate the effectiveness of educational program on handoff communication competencies.
\end{abstract}

Keywords: Handoff, Communication Competence, Nurses Interns, Educational Program

\section{Introduction}

Communication is essential to human interactions, without it, people cannot relate to those around them, make their needs and concerns known, or make sense of what is happening to them [2]. Effective communication among nurses is essential to ensure patient safety and deliver high quality of care [3]. The transfer of essential information and the responsibility for care of the patient from one health care provider to another is an integral component of communication in health care. This critical transfer point is known as a handoff. Handoff contribution to healthcare quality is being increasingly recognized as evidence grows linking communication defects to patient safety lapses. The
Joint Commission, the body that accredits hospitals and other healthcare organizations in the United States, recognized that handoff standardization could improve communication quality; it designated handoff standardization as a national patient safety goal in 2006 [4].

Nurses constitute the largest proportion of the multidisciplinary team, their role being to ensure that consistent care and appropriate treatment are provided to patients for 24 hours a day. Effective communication and coordination, both within the nursing team and between the wider multidisciplinary team, are essential to the fulfillment of this role, and one method of facilitating this is through the deliverance of handover [5]. Nursing communication may occur anytime during the shift working hours. However, the 
communication that occurs at shift change between the offgoing nurse (Sender) and incoming nurse (Receiver) is the most common form of communication among nurses, this way of communication is usually called the End of Shift Report [3]. The joint commission on accreditation of health care organization (JCAHO) defines handoff as "Interactive process of exchange patient specific information from one caregiver to another for the purpose of ensuring the continuity and safety of patient care" [6] [7]. Handoffs may also provide a positive form of stress relief and emotional support and promote team building or group cohesion. Ideally, each handoff is a conversation rather than a one way communication. Studies on information transfer consistently show that verbally transmitted information is liable to degradation and loss, so active engagement by the "recipient" is necessary to ensure adequate handoff [8] [9].

Multiple definitions of handoff are used to describe the event that occurs when the care of the patient is in transition between healthcare providers [3]. Patient's care handoffs is described as the exchange of patient's information between healthcare professionals, accompanying either a transfer of control or responsibility [8] [10]. Regardless if its known as handovers, sign-off and inter-shift report, handoffs occur when nurses provide related information about their patients to facilitate continuity of patientcare [11] [12]. Moreover, handoff is the transfer of information, and professional responsibility and accountability, between individuals and teams, within the overall system of care, giving of information is often regarded as the basic function of handover [5]. Information transfer is reported to ensure that continuity of care is achieved. Usually, this information is a synthesis of facts and notes collected during the care process from different sources such as health records, team members, changes and remarks on the patient condition over a period of time. Patient handoff between nurses at shift change has been an important process in clinical nursing practice, allowing nurses to report necessary patient information to ensure continuity of care and promote patient safety [13]. This highlights the connection between many important aspects such as patient information exchange as an input leads to better continuity of care and patient safety as desired outcomes.

The main aim of nursing handoff is to transfer accurate, relevant, and current clinical information about the patient which is necessary for continuity of care. Ideally, the aim of the handoff process is to achieve effective, safe, and high quality communication when the responsibility for the patient's care is transferred from one nurse to another [14]. Unfortunately, it is becoming increasingly apparent that any defect in communication system, in hospitals, compromises the patient safety [15]. Furthermore, Incomplete, confusing, unclear, misunderstood, and unstandardized, communication is ineffective and dangerous [5]. Ineffective handoff communication may lead to serious consequences such as incorrect patient treatment, delays in diagnosis and treatment, unnecessary tests and procedures, prolonged hospitalization, patient suffering and malpractice claims [16].
Many types of patient handoffs are introduced in the literature, including nursing shift changes; reporting of patient's conditions by physicians; reporting by staff leaving the unit for a short time; nursing and physician handoff from the emergency department to inpatient units, other hospitals, and critical patient laboratory results sent to physician offices. Recently many other handoff forms have been developed, such as the bedside report and the tape-recorded handoff [17].

In reviewing the literature related to the patient handoff process, it is important to consider communication competence. By understanding what behaviors influence the quality of the patient handoff, nurses can know how to enhance their competency in handoff communication regardless of how an organization standardizes the interaction. Improving the overall communication competence of nurses could lead to effective handoffs and reduced communication-related patient care errors. Communication competence is a core concept in interpersonal communication research and it can be defined as the knowledge of appropriate communication patterns in a given situation and the ability to use the knowledge. Competent communication includes information exchange which focuses on information seeking, giving and verifying as well as socio-emotional communication. [18] [19].

Information giving or provision is being related to the detail given in response to a direct question or offered without prompt. While information seeking is the ability to ask questions to get a more complete, accurate and current data of a patient's status at change of shift. The information verifying consists of clarifying, repeating, summarizing and anticipating. These behaviors are important to the handoff as a method of reducing the risk of miscommunication by assuring understanding. The socio-emotional communication is another one component of communication competence that focuses on enhancing trust relationship, concern, and warmth [18].

Nursing students should be prepared for and learn the process of effective communication that promotes patient safety. The knowledge and skill to carry out a handoff report may be briefly addressed in the classroom or simulation laboratory setting but is mastered from the observation of mentors and peers [20]. Moreover students interns are exposed to multiple clinical sites and witness variability in handoff practices among different institutions. Following graduation, new nurses rarely receive formalized handoff education. Instead, they often learn this important safety skill by modeling equally unskilled peers. This inconsistency in hand off preparation for student nurses and new nurses creates a latent safety risk [10]. Though there is recognition that handoff communication skills are essential components of undergraduate nursing education. There is little research regarding the best methods for providing this education on nursing students. The process to learn handoff communication is often unpredictable and dependent on clinical experiences. Safety education, including handoff education, may help build more highly reliable health care 
organizations by promoting safer communication skills [10]. So the aim of the present study is to examine the effectiveness of handoff educational program on nurses interns knowledge, and communication competence.

Significance:

An effective handoff supports the exchange of important information and continuity of care and treatment. However, the literature continues to highlight the consequences of ineffective handoffs that can leads to gaps in patient care and breaches in patient safety, including medication errors, wrongsite surgery, patient deaths, delays the course of treatment, patient dissatisfaction, and prolonged hospital stay [21]. Handoff communication is basic for health care providers, the aim of handoff should achieve safe, effective, comprehensive and high quality communication during the transitions of patients' care. Clinical environments are dynamic and complex, presenting many challenges for effective communication among health care providers, patients, and families. The dynamic and fast -paced environment of the intensive care unit demands efficiency during handoff that may compromise information exchange, the care for each patient demands an immediate knowledge of critical and highly complex data [22]. More over ensuring effective communication during shift report is particularly important in high stress environments such as Intensive Care Units [23], more importantly; nurses use the shift report information to make decisions and to build up the patient's care plan.

Shift handover is a common tradition among nurses; however, standard and effective handover and information communication skills are not taught formally during nursing academic education; rather, nurses learn such skills during their daily practice and from more experienced nurses. More over from the previous researcher's experiences as responsible for supervision of student interns during internship year, it was observed that many handoff communication problems were caused by nurse's interns in different shifts. In addition there is comparably limited literature describing the effects of handoff education on nursing student handoff communication skills [24]. So it is hoped that these handoff educational sessions will enhance and improve nurse's interns' handoff knowledge, and communication competence.

\section{Methodology}

\subsection{Research Aim\& Hypothesis}

The current study aimed to examine the effectiveness of handoff educational program on nurse's interns knowledge, and communication competence. This research was designed to test the hypotheses that there is significant difference in the knowledge regarding handoff, and communication competence among nurse's interns before and after the participation in handoff educational program.

\subsection{Design}

Quasi - experimental study design was utilized to examine the effect of handoff educational program on nurse's interns' handoff knowledge, and communication competence.

\subsection{Setting}

The study program was conducted in all intensive care units with different specialties which affiliated with Kaser El Ainy hospital where nurse's interns were trained.

\subsection{Sample}

Study sample composed of 30 nurses interns who were undertaking their internship in intensive care units during the academic year 2016-2017. According to internship rotation plan, one group of nurses interns who start their training in ICU at the beginning of internship year and who complete the educational program sessions successfully as well as different follow up periods of the program were constitute the study sample.

\subsection{Tool}

The following tools were utilized as follows:

\subsubsection{Demographic Data Sheet}

Demographic data sheet: was developed by the researchers and it included background characteristics of nurses interns, such as: age, sex, type of education before joining the faculty (secondary school degree or technical institute degree), previous handoff knowledge and previous work experiences during their study years.

\subsubsection{Handoff Knowledge Questionnaire}

Handoff knowledge questionnaire was developed by the researchers based on the literature review [25] [26] [27] [28], to assess nurse's interns' knowledge about handoff. It consisted of (15) Multiple-choice questions, covering the following: Handoff definition and related concepts (3 items), importance and benefits of handoff (3 items), components of handoff and communication competence (3 items) methods and structure of handoff (3 items), and Handoff communication tools ( 3 items).

The scoring system for the questionnaire sheet consisted of score (one) for correct answer and (zero) for the wrong answer for Multiple-choice questions. The scoring levels were arranged as follow $60 \%$ and more for satisfactory knowledge. Less than $60 \%$ is for unsatisfactory knowledge [29]. It was utilized during different periods of assessment (pre-program, immediately after program and 3 months later)

\subsubsection{Handoff Communication Competence Observational Checklist}

Handoff communication competence observational checklist was developed by [1] and modified by the researchers to measure hand-off communication competence of nurses interns at the patient bedside handover as a one-way report from the outgoing to the incoming nurses interns. It contains the following subscales: information giving (10 items), facilitating information seeking (5 items), information verifying (3 items) and socio-emotional communication (7 
items). The scoring system was as follows: 1 for done and zero for not done. The total score is 25 , score 14.9 which represents $(59.9 \%)$ indicates low competence, score from 15 18.5 which represents $(60-74 \%)$ indicates moderate competence and finally score 18.9 which represents $(75 \%$ and more) indicates high competence. It was utilized during different periods of assessment (pre-program, immediately after program and 3 months later).

\subsection{Tool Reliability and Validity}

Handoff communication competence observational checklist was tested for its reliability, the measure demonstrated good internal consistency $(\alpha=.95)$. The tools contents were developed and tested for its content validity through five expertise from nursing administration department. Based on their recommendations the necessary modifications were made.

\subsection{The Pilot Study}

A pilot study was conducted on 10 percent of study sample in order to test the clarity and validity of the study tools content, add or omit questions and assess time needed to respond to each questionnaire. Necessary modifications were done.

\subsection{Ethical Consideration}

Official permissions were obtained from hospital's director and nursing director of the previous selected hospital to conduct the study at the selected units. They were assured that the data is confidential and used only for research purposes. The researchers ensured that the correct procedures were undertaken concerning informed consent, autonomy, anonymity and maintenance of the subjects confidentiality.

\subsection{Procedure}

Prior to implementation of the handoff educational program, an official permission was obtained from the nursing supervisors of the selected units. This was intended to facilitate data collection and to explain study purpose. At the beginning of the internship year, nurse's interns were invited to participate in the program. The researchers explained the study purpose and procedures for the selected sample. Student nurses were further informed that the participation was voluntary and that study findings would be presented group wise and no individual would be recognized.

A knowledge test questionnaire was then handed to nurses interns on their work place to measure their knowledge about handoff and related concept using the developed handoff knowledge questionnaire. Because incoming nurse interns play little role in bedside handoff, observations of the students interns as outgoing in different shifts during patient bedside handoff was conducted to measure their communication competence while they report to incoming students interns through utilizing handoff communication competence observational checklist. So each nurse intern was given the opportunity to be observed as outgoing nurse through 3 intermittent observation. Arrangement with head nurses of the selected units was done by the researchers to allow outgoing interns to report incoming one. The preprogram data were carried out from $1^{\text {st }}$ of October to mid of November 2016.

After collecting pre-program data, the studied sample was divided into two groups according to their shift rotation and the program educational sessions were held twice a week. Each session lasted an hour, and the total educational sessions for the program were 5 sessions. Contents of the program sessions were as follows: Handoff definition and related concepts $\left(1^{\text {st }}\right.$ session), importance and benefits of handoff ( $2^{\text {nd }}$ session $)$, components of handoff and communication competence $\left(3^{\text {rd }}\right.$ session) methods and structure of handoff ( $4^{\text {th }}$ session) and Handoff communication tools $\left(5^{\text {th }}\right.$ session). These sessions were followed by supervision of nurse's interns in their clinical areas covering different work shifts in order to provide each nurse with support, and help them to use new knowledge. Different teaching and learning methods were used during conducting program: lecture, group discussion, demonstration, and work in small groups. The program educational sessions were carried out from $1^{\text {st }}$ of December 2016 to $1^{\text {st }}$ of January 2017.

To assess the immediate impact of the program on nurses interns handoff knowledge and communication competence, the previous instruments were utilized immediately after the program started from the mid of January 2017to end of February 2017. In addition to measure nurse's intern's retention of handoff knowledge as well as handoff communication competencies, the previous questionnaires were utilized 3 months after program implementation started from June 2017 to mid of July 2017.

\subsection{Statistical Design}

The collected data was scored, tabulated by using statistical package for the social science (SPSS) program version 20 and analyzed by using the following tests: frequencies and mean and standard deviation were used as measures of central tendency and dispersion respectively for qualitative data Test of significance was performed to test study hypothesis (F test). Comparison between two groups and more was done using Chi-square test. Correlation between variables was evaluated using Pearson's correlation coefficient (r). Significance was adopted at $\mathrm{p}<0.05$ for interpretation of results of tests of significance.

\section{Results}

Table 1. Demographic Characteristics of Study Sample (No 30).

\begin{tabular}{llll}
\hline \multicolumn{2}{l}{ Demographic data } & NO & \% \\
\hline Age: & 22- less than 24 & 29 & 96.7 \\
1 & 24 and more & 1 & 3.3 \\
2 & & & \\
Sex: & Male & 11 & 63.7 \\
1 & Female & 19 & 36.3. \\
2 & Type of education: & & \\
3 & r & & \\
\hline
\end{tabular}




\begin{tabular}{|c|c|c|c|}
\hline \multicolumn{2}{|c|}{ Demographic data } & \multirow{2}{*}{$\frac{\text { NO }}{25}$} & \multirow{2}{*}{$\begin{array}{l}\frac{\%}{83.3} \\
8\end{array}$} \\
\hline 1 & Secondary school & & \\
\hline 2 & Technical institute & 5 & 16.7 \\
\hline 3 & Previous Work experience: & & \\
\hline 1 & yes & 13 & 43.3 \\
\hline 2 & No & 17 & 56.7 \\
\hline
\end{tabular}

Data in table 1 showed that the majority of studied sample $(96.7 \%)$ was in age group ranged between 22- less than 24 years, as well as the highest percentage of them $(63.7 \%)$ were male. Regarding their type of education data in the same table showed that the majority of them $(83.3 \%)$ were graduated from secondary school. It is clear also that $56.7 \%$ of studied sample did not have previous work experiences.

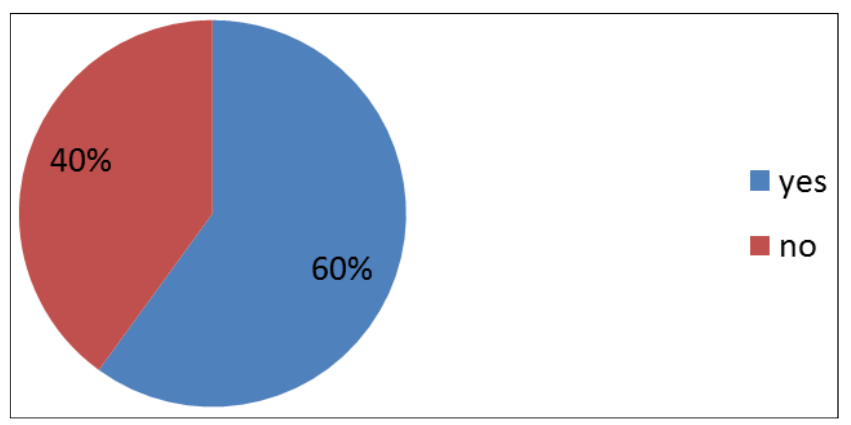

Figure 1. Frequency Distribution of Study Sample regarding Previous Handoff Knowledge (No 30).

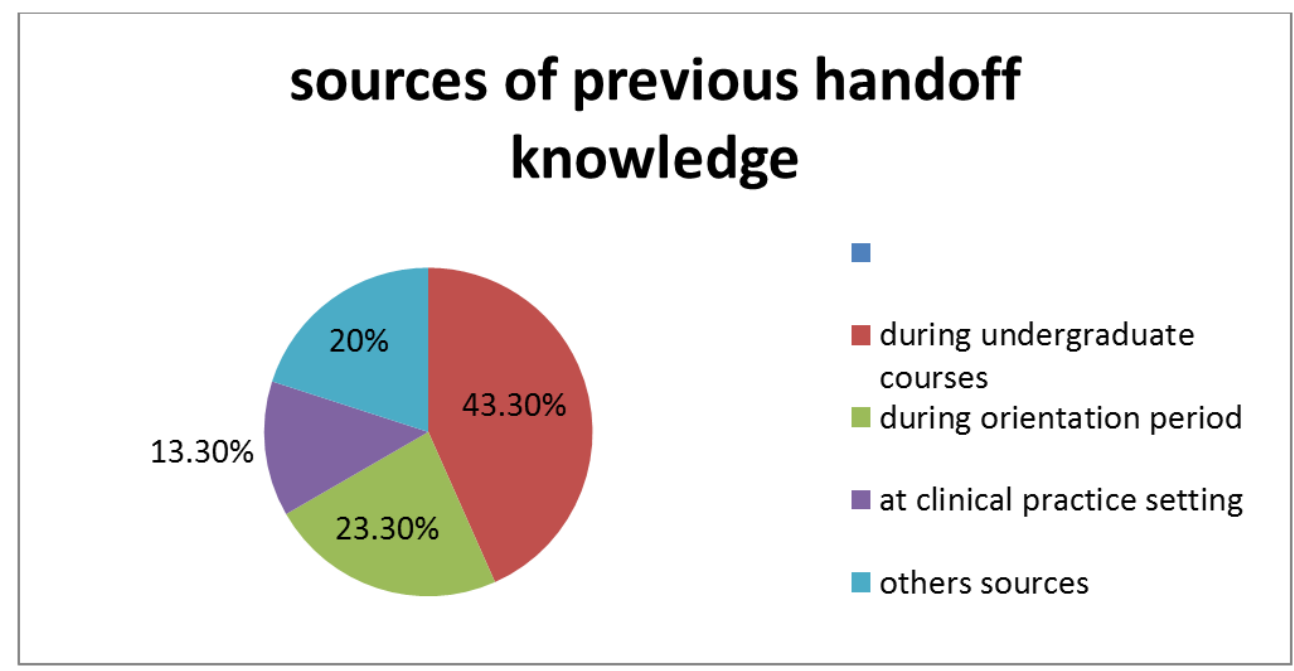

Figure 2. Sources of Previous Handoff knowledge among study sample (no 30).

Data in figure $1 \& 2$ illustrated that $60 \%$ of studied sample had previous handoff knowledge and $43.30 \%$ of them gain this knowledge during undergraduate course.

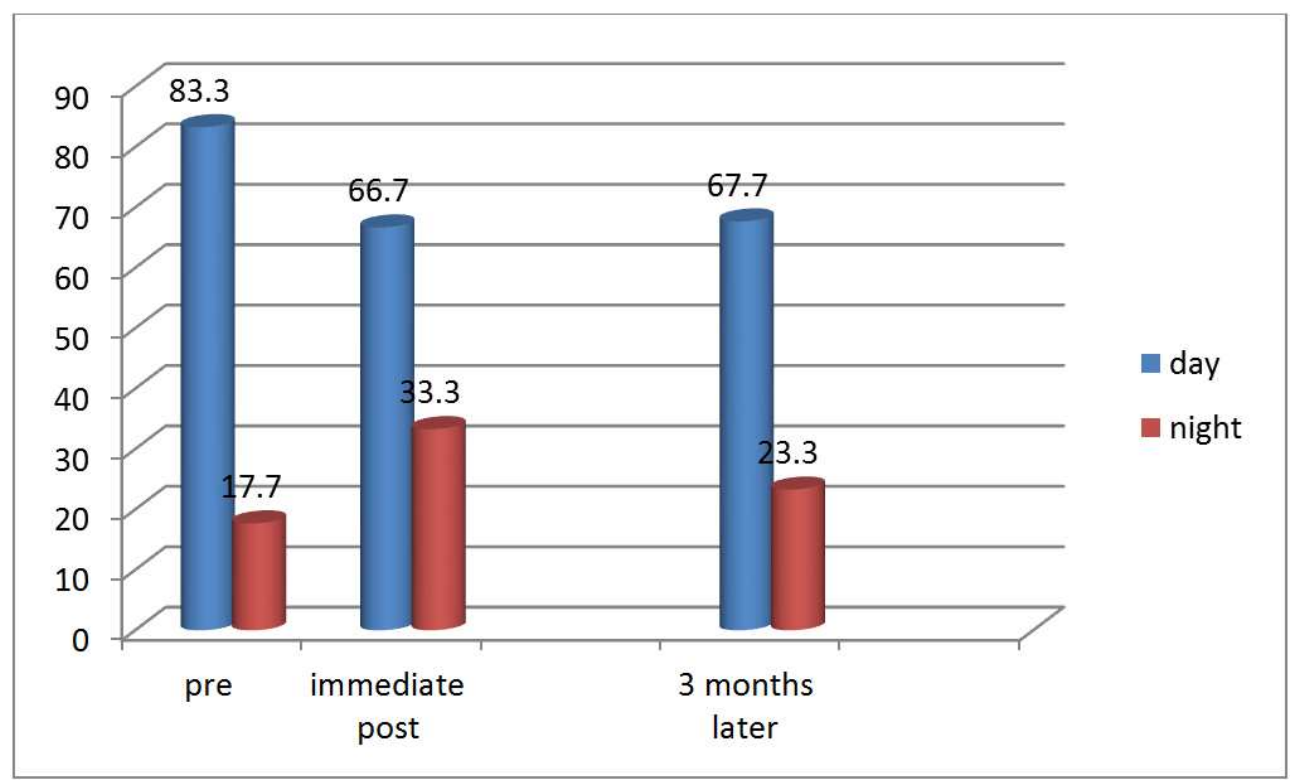

Figure 3. Frequency Distribution of Study Sample regarding work shift as work related variable during different periods of assessment (No 30).

The above figure showed that the highest percentage of nurses interns were working day shift during different periods of assessment. 
Table 2. Comparison of Nurses Interns regarding their Levels of Handoff Knowledge dimensions during Different Periods of Assessment (30).

\begin{tabular}{|c|c|c|c|c|c|c|c|c|}
\hline \multirow{2}{*}{ handoff knowledge dimensions } & \multicolumn{2}{|c|}{ pre program } & \multicolumn{2}{|c|}{ post program } & \multicolumn{2}{|c|}{3 months post program } & \multirow{2}{*}{$\begin{array}{l}\text { chiq } \\
\text { square }\end{array}$} & \multirow{2}{*}{ p value } \\
\hline & NO & $\%$ & NO & $\%$ & NO & $\%$ & & \\
\hline \multicolumn{9}{|l|}{ 1-Handoff concept: } \\
\hline 1- Satisfactory & 18 & $60 \%$ & 20 & $66.66 \%$ & 28 & $93.3 \%$ & \multirow[t]{2}{*}{33.216} & \multirow{2}{*}{$.000 *$} \\
\hline 2-Unsatisfactory & 12 & $40 \%$ & 10 & $33.33 \%$ & 2 & $6.6 \%$ & & \\
\hline \multicolumn{9}{|l|}{ 2-Importance and benefits } \\
\hline 1-Satisfactory & 26 & $86.6 \%$ & 28 & $93.3 \%$ & 30 & $100 \%$ & \multirow[t]{2}{*}{17.64} & \multirow{2}{*}{$.000 *$} \\
\hline 2- Unsatisfactory & 4 & $13.3 \%$ & 2 & $6.6 \%$ & 0 & 0 & & \\
\hline \multicolumn{9}{|c|}{ 3-Components of handoff \&communication competence } \\
\hline 1-Satisfactory & 15 & $50 \%$ & 17 & $56.6 \%$ & 28 & $93.3 \%$ & \multirow[t]{2}{*}{25.35} & \multirow{2}{*}{$.000^{*}$} \\
\hline 2- Unsatisfactory & 15 & $50 \%$ & 13 & $43.3 \%$ & 2 & $6.6 \%$ & & \\
\hline \multicolumn{9}{|l|}{ 4-Methods and structure of handoff } \\
\hline 1- Satisfactory & 21 & $70 \%$ & 26 & $86.6 \%$ & 30 & $100 \%$ & \multirow[t]{2}{*}{21.18} & \multirow{2}{*}{$.002 *$} \\
\hline 2-Unsatisfactory & 9 & $30 \%$ & 4 & $13.3 \%$ & 0 & 0 & & \\
\hline \multicolumn{9}{|l|}{ 5-Handoff communication tools } \\
\hline 1- Satisfactory & 14 & $46.6 \%$ & 30 & $100 \%$ & 30 & $100 \%$ & \multirow[t]{2}{*}{59.09} & \multirow{2}{*}{$.000 *$} \\
\hline 2- Unsatisfactory & 16 & $53.3 \%$ & 0 & 0 & 0 & 0 & & \\
\hline
\end{tabular}

Significant at $\mathrm{p}<0.05 *$

It was clear from table 2 that there was statistical significant and marked improvement in nurses interns' levels of handoff knowledge dimensions during different periods of assessment. Regarding the dimensions of handoff concept and Components of handoff \&communication competence it was seen that the majority of studied sample had satisfactory score 3 months post program compared to preprogram and immediately post program period $(93.3 \%, 60 \% \& 66.66 \%)$ and $(93.3 \%, 50 \%, \& 56.6 \%)$ respectively $(\mathrm{p}=.000 *)$. Also it was clear that $100 \%$ of nurses interns scored satisfactory level3 months post program relative to pre and immediately post program regarding the following three dimensions (importance and benefits, methods and structure of handoff and handoff communication tools) and all differences were statistically significant.

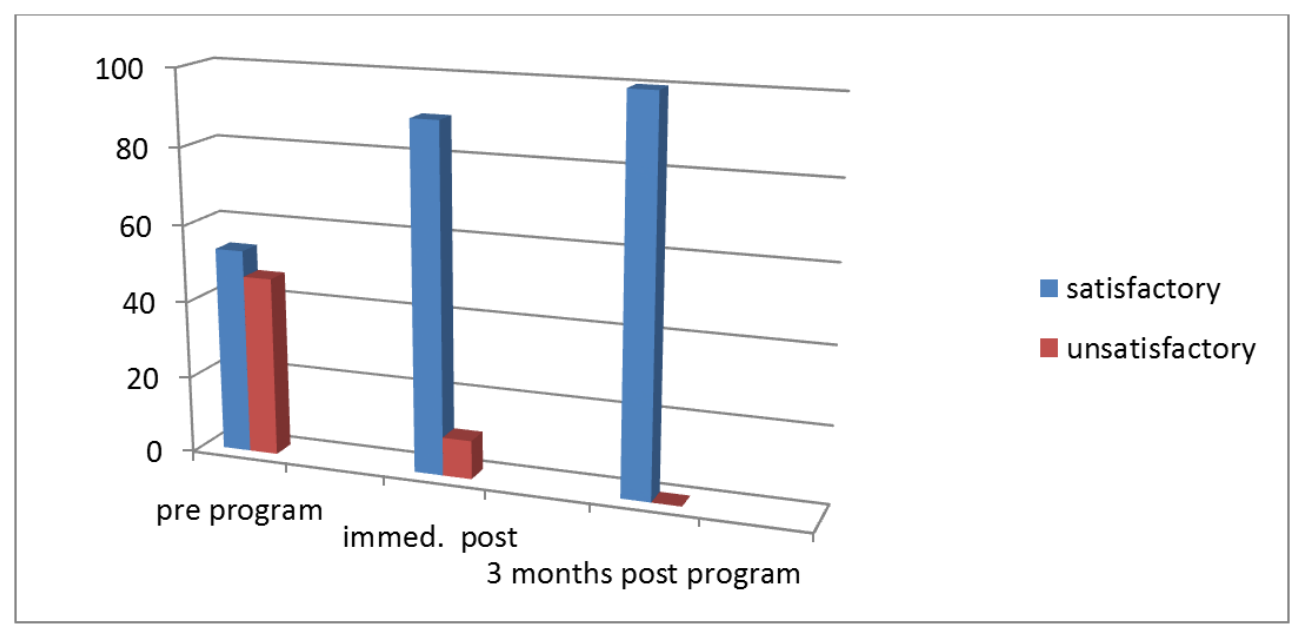

Figure 4. Frequency distribution of nurse's interns regarding their total handoff knowledge levels during different periods of assessment.

Data figure 4 showed marked improvement in total handoff knowledge levels among nurses interns during different periods of assessment as $90 \%$ of nurses interns had satisfactory score immediately post program with further improvement 3 months post program as $100 \%$ scored satisfactory level relative to only $53.33 \%$ in pre- program.

Table 3. Comparison of Nurses Interns Mean Scores regarding Handoff Communication Competencies dimensions during Different Periods of Assessment.

\begin{tabular}{|c|c|c|c|c|c|c|c|c|}
\hline \multirow{2}{*}{$\begin{array}{l}\text { Handoff Communication Competencies } \\
\text { dimensions }\end{array}$} & \multicolumn{2}{|c|}{ pre program } & \multicolumn{2}{|c|}{ post program } & \multicolumn{2}{|c|}{3 months post program } & \multirow{2}{*}{$\mathbf{F}$} & \multirow{2}{*}{$\mathbf{P}$} \\
\hline & Mean & SD & Mean & SD & Mean & SD & & \\
\hline 1-Informatuion giving $(10)^{*}$ & 6.7333 & 2.2273 & 7.566 & 2.726 & 8.5333 & 1.3321 & 5.779 & $.004^{*}$ \\
\hline 2-Facilitating information seeking (5)* & 3.2000 & 1.2429 & 4.100 & 1.323 & 4.7333 & .58329 & 14.11 & $.000^{*}$ \\
\hline 3 -Information verifying $(3)^{*}$ & 2.0000 & 98261 & 2.350 & 1.0541 & 2.9333 & .36515 & 13.58 & $.000^{*}$ \\
\hline 4-Socioemotional communication $(7)^{*}$ & 6.1333 & 1.795 & 6.133 & 1.5564 & 6.5333 & .81931 & 1.841 & .165 \\
\hline total scores $(25)^{*}$ & 18.066 & 5.2845 & 20.15 & 5.7159 & 22.733 & 1.3113 & 9.069 & $.000^{*}$ \\
\hline
\end{tabular}

()* refers to maximum score of dimension

Significant at $\mathrm{p}<0.05 *$ 


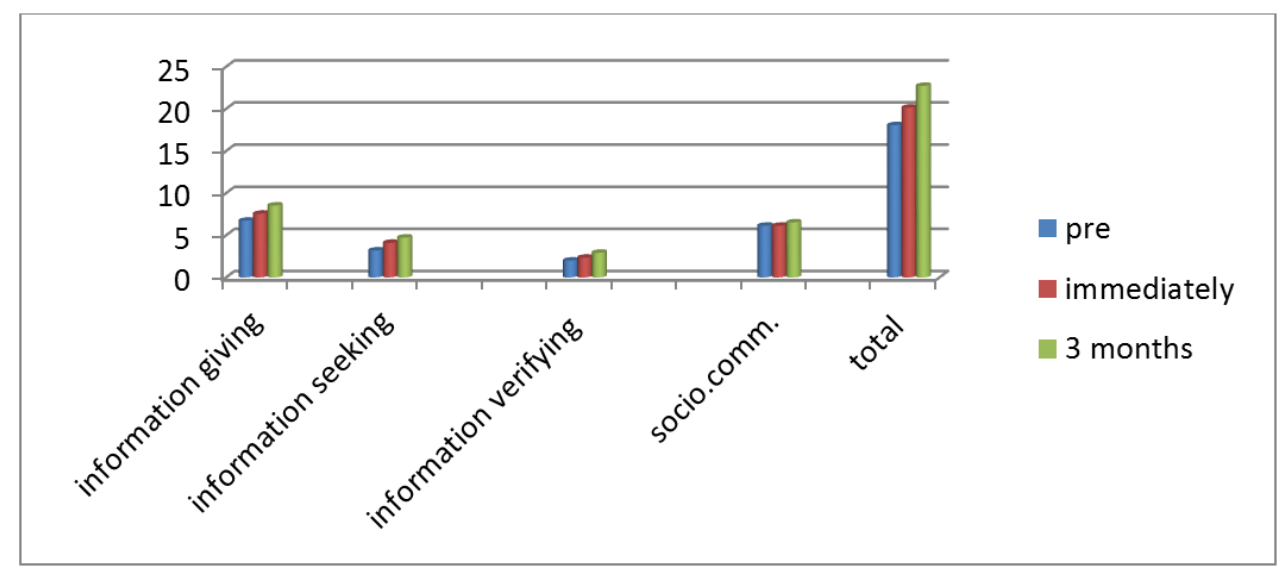

Figure 5. Comparison of Nurses Interns' Mean Scores regarding Handoff Communication Competencies Dimensions during Different Periods of Assessment.

Data in table 3 and figure 5 showed statistical significant differences in nurses interns mean scores regarding most of dimensions of handoff communication competencies 3 months post program relative to pre and immediately post program period except for Socio-emotional communication dimension which was reflected in total mean scores respectively $(18.066 \pm 5.2845,20.15 \pm 5.7159,22.733 \pm 1.3113) \mathrm{F}=9.069 \mathrm{P}=.000 *$

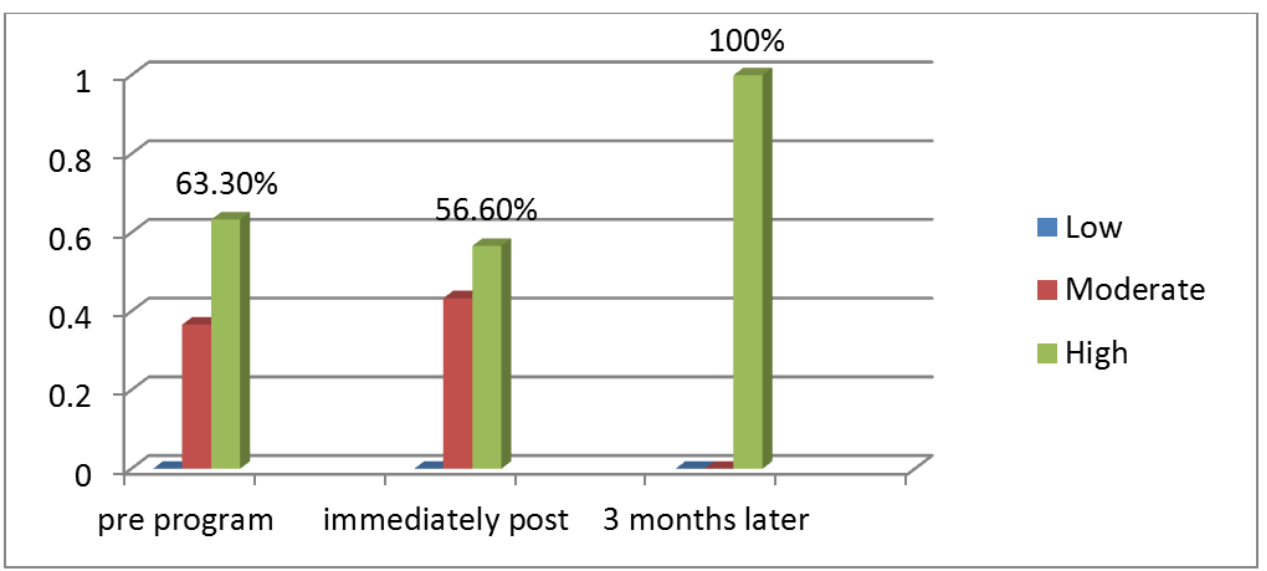

Figure 6. Frequency Distribution of Nurses Interns Regarding Levels of total Handoff Communication Competences during Different Periods of Assessment.

It is clear from figure 6 that there was a marked improvement in nurse's interns levels of total handoff communication competences, it was shown that nurses interns had generally high score in the preprogram period $(63.3 \%)$ and none of them scored low during different periods of assessment. Further improvement was seen 3 months post program as $100 \%$ of them scored high competencies

Table 4. Correlation between Nurses Interns' total Handoff Knowledge and Communication Competencies dimensions during Different Periods of Assessment.

\begin{tabular}{|c|c|c|c|c|c|c|}
\hline \multirow{3}{*}{$\begin{array}{l}\text { Handoff Communication Competencies } \\
\text { Dimensions }\end{array}$} & \multicolumn{6}{|c|}{ Total Handoff Knowledge } \\
\hline & \multicolumn{2}{|c|}{ pre program } & \multicolumn{2}{|c|}{ immediately post program } & \multicolumn{2}{|c|}{3 months post program } \\
\hline & $\mathbf{r}$ & $\mathbf{p}$ & $\mathbf{r}$ & $\mathbf{p}$ & $\mathbf{r}$ & p \\
\hline 1-Information giving & -147 & .439 & ,329 & $0.02 *$ & .302 & .105 \\
\hline 2-Facilitating information seeking & -.050 & .793 & .180 & .341 & .159 & .401 \\
\hline 3-Information verifying & .105 & .579 & .173 & .362 & .000 & 1.000 \\
\hline 4-Socioemotional communication & -.185 & .327 & .356 & $0.04 *$ & .189 & .318 \\
\hline Total Communication Competencies & -.117 & .539 & .319 & $.002 *$ & .260 & .166 \\
\hline
\end{tabular}

Significant at $\mathrm{p}<0.05 *$

It was clear from table 4 that there was only a statistical significant correlation immediately post program between nurses interns' total handoff Knowledge and total communication competencies $(\mathrm{r}=.319, \mathrm{p}=002 *)$. As well as a statistical significant correlation between total handoff Knowledge and both Information giving and Socio-emotional communication dimensions $\left(\mathrm{r}=, 329, \mathrm{p}=0.02 *, \mathrm{r}=.356, \mathrm{p}=0.04^{*}\right)$ respectively. While no any statistical significant correlation was found in pre- program and 3 months post program implementation. 
Table 5. Differences in Handoff Communication Competencies Mean Scores among Nurses Interns by Work Shift as Work Related Variable post-program (No 30).

\begin{tabular}{|c|c|c|c|c|c|c|c|c|}
\hline \multirow{3}{*}{$\begin{array}{l}\text { handoff communication competencies } \\
\text { dimensions }\end{array}$} & \multicolumn{4}{|c|}{ immediately post program } & \multicolumn{4}{|c|}{3 months later } \\
\hline & \multicolumn{2}{|c|}{ day shift(20) } & \multicolumn{2}{|c|}{ night shift(10) } & \multicolumn{2}{|c|}{ day shift(23) } & \multicolumn{2}{|c|}{ night shift(7) } \\
\hline & Mean & SD & Mean & SD & Mean & SD & Mean & SD \\
\hline 1-Information giving(10) & 6.35 & 3.70 & 7.100 & 2.72 & 8.6087 & 1.30520 & 8.2857 & 1.49603 \\
\hline $\mathrm{p}$ value & .536 & & & & .619 & & & \\
\hline 2-Facilitating information seeking(5) & 3.150 & 1.66 & 4.100 & 1.100 & 3.8522 & 64728 & 5.0000 & .00000 \\
\hline $\mathrm{p}$ value & .074 & & & & $.024^{*}$ & & & \\
\hline 3-Information verifying(3) & 1.700 & 1.30 & 1.900 & .994 & 2.9130 & .41703 & 3.0000 & .00000 \\
\hline $\mathrm{p}$ value & .645 & & & & .328 & & & \\
\hline 4-Socioemotional communication(7) & 5.60 & 2.22 & 6.000 & 1.49 & 6.6087 & .78272 & 6.2857 & .95119 \\
\hline $\mathrm{p}$ value & .563 & & & & .435 & & & \\
\hline total handoff communication competencies & 16.800 & 7.99 & 19.100 & 5.04 & 22.7826 & 1.31275 & 22.5714 & 1.39728 \\
\hline $\mathrm{p}$ value & .346 & & & & .730 & & & \\
\hline
\end{tabular}

The above table illustrated that there was no statistical significant differences between night and work shift nurses interns regarding their mean scores of handoff communication competencies dimensions immediately post program, although nurses interns in night shift had highest mean scores compared to those in day shift, it is not proved to be statistically significant. Data in the same table showed a statistical significant differences between day and night shift nurses interns mean score only in information seeking dimension 3 months post program as night shift had highest mean scores compared to those in day shift, $\left(\mathrm{p}=.024^{*}\right)$.

Table 6. Relationship between Nurses Interns handoff knowledge and communication competencies and their Demographic variables.

\begin{tabular}{|c|c|c|c|c|}
\hline \multirow{2}{*}{ Demographic data } & \multicolumn{2}{|c|}{ handoff knowledge } & \multicolumn{2}{|c|}{ handoff competencies } \\
\hline & Mean & SD & Mean & SD \\
\hline \multicolumn{5}{|l|}{ 1-Sex: } \\
\hline male & 8.909 & 3.144 & 19.272 & 2.53 \\
\hline female & 8.842 & 1.803 & 17.368 & 6.326 \\
\hline $\mathrm{P}$ value & .949 & & .256 & \\
\hline \multicolumn{5}{|l|}{ 2-Education: } \\
\hline secondary school & 8.8400 & 2.44404 & 17.8800 & 5.78302 \\
\hline technical & 9.0000 & 1.87083 & 19.0000 & .70711 \\
\hline $\mathrm{P}$ value & .987 & & .855 & \\
\hline \multicolumn{5}{|c|}{ 3-Previous work experience: } \\
\hline yes & 9.384 & 2.50 & 18.230 & 5.932 \\
\hline no & 8.470 & 2.82 & 17.941 & 4.917 \\
\hline$P$ value & .854 & & .436 & \\
\hline \multicolumn{5}{|c|}{ 4-Previoushandoff knowledge: } \\
\hline yes & 9.1667 & 2.09341 & 20.5000 & 6.147 \\
\hline no & 8.4167 & 2.67848 & 16.4444 & 2.110 \\
\hline$P$ value & .988 & & $020 *$ & \\
\hline
\end{tabular}

It was clear from table 6 that there was only a statistical significant relationship between handoff communication competencies and nurses interns previous handoff knowledge $\left(\mathrm{P}=.020^{*}\right)$. While no other relationships were found between study variables and other demographic variables.

\section{Discussion}

Dynamic and complex clinical environments present many challenges for effective communication among health care providers. The goal of nursing handoff is to communicate and exchange accurate, relevant and up-to-date clinical information about the patient which is necessary for continuity of care. Clinical handoff is one of the most important issues to consider when ensuring the continuity of patient care and safety. An effective handoff supports the transition of critical information and continuity of care and treatment [17]. The practice of handover between health professionals is an everyday practice, but a potentially risky aspect of patient care. Miscommunication of information can result in inadequate or unsafe care [5]. A nursing handoff, or handover, is a complex communication process that transfers essential information, responsibility, and accountability for the care of a patient from one nursing professional to another. Handoff education has been identified as a quality and safety education in Nursing (QSEN) pre-licensure competency [30].

The current study results support the research hypotheses which revealed that, there is significant difference in the knowledge regarding handoff, and communication competences among nurses' interns before and after the participation in handoff educational program. Regarding nurse's intern's levels of handoff knowledge dimensions during different periods of assessment, the current study results revealed that there was statistical significant and marked improvement in nurse's interns' levels of handoff knowledge dimensions during different periods of assessment regarding most of handoff knowledge dimensions. As the majority of studied sample had satisfactory score 3 months 
post program compared to preprogram and immediately post program period. This result is consistent with [17], who found a significant difference at pre and post educational session regarding nurse's handoff knowledge and they added that, inadequate handoff of patient information carries significant risks for individual clinicians, their organizations and for their patients. So a Sufficient and relevant information through educational sessions should be exchanged to ensure patient safety. More over without handoff education, the nursing students in this study lacked awareness of the importance and benefits of handoff, methods of handoff as well as components of handoff and communication competence [10].

From the investigators' point of view, engaging nurses interns in handoff educational program had a positive impact on increasing their knowledge as they become aware about essential concepts of handoff, methods and structures, in addition they gain knowledge about importance of proper handoff for them and for their patients. Moreover they became knowledgeable about socio-emotional communication as a core concept in interpersonal communication.

Regarding the nurses intern's handoff communication competencies during different periods of assessment the present study revealed that there was a statistical significant differences in nurses interns mean scores regarding most of dimensions of handoff communication competencies 3 months post program relative to pre and immediately post program period. In addition there was a marked improvement in their levels of total handoff communication competences 3 months post program as all of them scored high competencies. From the researchers' point of view this result support the positive effect of the program as the knowledge they gained in the educational program help them to practice handoff communication well. In the same issue [20] found that after implementation of handoff educational sessions the nursing students had a better grasp of the background and rationale for an effective hand-off report. As a result, students began to recognize pertinent critical health information that needed to be communicated to their nurse. Nursing students also conveyed feelings of confidence and empowerment in the performance of hand-off communication. This result is consistent with [17], as they reported a statistical significant difference at pre and post educational session regards the overall quality of handoffs received described as excellent or good. This result is expected after nurses know, what, how and when the right handoff and its effect on quality of patient care applied at educational session.

Moreover when the dimensions of handoff communication competencies were investigated during different periods of assessment, study results showed statistical significant differences in most of related dimensions (information giving, seeking and verifying) 3 months post program relative to pre and immediately post program. In this respect [31] reported that enhanced training and systems for effective and safe handoff are essential in maintain high standards of continuity of care. In addition, [21] Found that nurses scores increased significantly in handoff after the study intervention in terms of patient safety through updating their caring program, maintaining the continuity of care, and improving the quality of inter-shift information communication. On the same line, [18] stated that nursing handoff is a critical issue in a patient's care that happens two to three times every day. Handoff must facilitates a respectful, concerned, comprehensive and accurate dialogue between nurses rather than a one-way nursing handoff report offers an opportunity for nurses to collaborate, providing different perspectives about patient needs, identifying areas of concern, and perhaps preventing mistakes based on misinformation or inaccurate information.

From the researchers' point of view engaging nurses in handoff educational program increased their competencies regarding explaining treatment needed by the patient, endorsing services needed for the patient, providing relevant historical information about the patients, and answering the other nurse's questions thoroughly. In addition during bedside handoff the outgoing nurse interns encouraging the incoming one to ask questions and seek information, answering questions of incoming nurse related to the patient's needs. As well as reviewing important or complex information to make sure it correctly understood and making sure that all explanations and directions were clearly understood. In this respect [17], reported that nursing handoff is to communicate and exchange accurate, relevant, and upto-date clinical information about the patient that is necessary for continuity of care. In addition, [32] noted that the handoff involves both a transfer of knowledge as well as authority and responsibility.

Regarding socio-emotional communication as one dimension of communication competence, the current study results revealed increased mean scores of nurse's interns immediately post program and 3 months later. In this respect, [20] stated that collaborative inter professional communication are essential elements of the transfer of crucial patient information and the socio-emotional communication is another one component of communication competence that focuses on fostering warmth, trust, and concern during handoff [18].

Regarding the correlation between nurses' interns total handoff knowledge and communication competencies dimensions during different periods of assessment, results of the current study revealed that there was only a statistical significant correlation immediately post program between nurses interns' total handoff Knowledge and total communication competencies. As well as a statistical significant correlation between total handoff Knowledge and both information giving and socio-emotional communication dimensions. From the researcher's point of view, this result can be explained as, the training program has its immediate positive effect and nurse's intern's starts to apply the knowledge they gained which was reflected on their communication competence, and they recognized pertinent critical health information that needed to be communicated to their peers. In the same issue [30] 
concluded that nursing students performed significantly better when providing and receiving handoff after they gain handoff knowledge in training program. Additionally, [33] has described the positive effect of handoff training in handoff receiver skills. Without handoff education, the nursing students lacked awareness of the importance of an active handoff recipient in creating a shared mental model. Consistently with the current research result [34] describes the necessity of both provider and receiver actively participating in the co-construction of the oncoming caregiver's understanding of the patient in order to promote patient safety. In the same issue [30] found that the nursing handoff educational training program improved handoff communication skills in nursing students.

When mean scores of nurses interns regarding hand off communication competencies were investigated in relation to work shift as work related variable, results of the current study revealed that there was a statistical significant differences between day and night shift nurses interns mean score only in information seeking dimension 3 months post program as night shift had highest mean scores compared to those in day shift. This result is contradicted with [35] who found that nurses who worked 8 hours shift report proper handoff quality than those work 12 hours shift. From the researcher point of view multiple work environment in day shift might affect the handoff practice as multiple interruptions, noisy environment and medical round which causing multiple distraction and leads to sharing of information quickly which in turn lead to incomplete and inaccurate report.

Regarding the relationship between nurses intern's handoff knowledge and communication competencies and their demographic variables, the current study revealed that, there was only a statistical significant relationship between handoff communication competencies and nurses intern's previous handoff knowledge while no other relationships were found between study variables and other demographic variables. From the researchers' point of view this could be related to that the highest percentage of studied sample reported that they gain previous handoff knowledge during undergraduate course and in clinical orientation which in turn affect their overall handoff communication competencies. This result is consistent with [36] who conclude that there was no relationship between nurses handoff practice and their demographic variables as age, gender, educational statues and experiences.

\section{Conclusion}

Results of the current study revealed that there was statistical significant and marked improvement in nurse's interns' levels of handoff knowledge dimensions as well as statistical significant differences in their mean scores of handoff communication competence during different periods of assessment. The current study provide evidence that handoff educational program enhance nurses interns handoff communication competence.
Based on study findings the following were recommended by the researchers:

a. Handoff communication skills should taught formally during nursing academic education concerning the way that information is given, verified as well as all handoff communication competencies during process of patient bedside handoff.

b. - Regular and permanent schedule by clinical instructors should be conducted for observing nurses interns during handoff process covering different work shifts in order to provide each nurse with support, and help them to use new knowledge.

c. -Collaboration between hospital staff and faculty staff to enhance nurse's intern's handoff communication competencies at the beginning of each clinical orientation as well as throughout the internship year.

d. First line nurse manager must act as a role model for demonstrating effective handoff communication skills for all staff nurses as well as students interns.

e. -Future researches with larger sample sizes and multiple settings are recommended to substantially evaluate the effectiveness of educational program on handoff communication competencies.

f. -More studies to investigate the effects of standardized shift handover protocols on nurses' satisfaction and nursing error incidence rate in other caring units is recommended.

\section{References}

[1] Cegala, D. J., Coleman, M. T., \& Turner, J. W. (1998). The development and Partial Assessment of the Medical Communication Competence Scale. Health Communication, 10(3), 261-288.

[2] Casey, A., (2011): Effective communication: Principle of Nursing Practice E., 25(32), pp.2007-2010.

[3] Al Ibrahim, M. (2014): Improving Nursing Handoff Process in the Cardiovascular Intensive Care unit. Published master thesis in Quality \& Safety in healthcare management. Institute of Leadership Royal College of Surgeons in Ireland.

[4] Meghan B. Lane-Fall, M. S. H. P., Amber K. Brooks, Sara A. Wilkins, B. S., Joshua J. Davis, B. A., Lee Ann Riesenberg (2014): Addressing the Mandate for Hand-off Education. A Focused Review and Recommendations for Anesthesia Resident Curriculum Development and Evaluation. The American Society of Anesthesiologists, Inc. Lippincott Williams \& Wilkins. Anesthesiology 2014; 120:218-29.

[5] DAVIS, c. Coetzee, c.m. Kyriacos, u. (2013): OPTIMISING THE NURSING SHIFT HANDOVER IN PAEDIATRIC INTENSIVE CARE. Published Master Thesis. Faculty of Health Sciences. UNIVERSITY OF CAPE TOWN. Page 12, 13.

[6] Joint Commission on Accreditation of Healthcare Organizations National Patient Safety Goals: critical access hospital and hospital national patient safety goals. Comprehensive Accreditation Manual for Hospitals: The Official Handbook, Oakbrook Terrace, IL, 2006. 
[7] Emily S. Patterson, Robert L. Wears, M. D (2010): Patient Handoffs: Standardized and Reliable Measurement Tools Remain Elusive. The Joint Commission Journal on Quality and Patient Safety Volume 36 Number 2.

[8] Riesenberg, L. A (2012): Shift-to-shift handoff research: Where do we go from here? J grad Med Educ; 4:4-8.

[9] Cohen MD, Hilligoss PB (2010): The published literature on handoffs in hospitals: Deficiencies identified in an extensive review. Qual Saf Health Care. 19:493-7.

[10] Margaret A. A, Yvonne L. W. (2015): Evaluation of a nursing handoff educational bundle to Improve nursing student handoff communications: A pilot study. Journal of Nursing Education and Practice 2015, Vol. 5, No.8.

[11] Australian Council for Safety and Quality in Health Care (2005): Clinical handover and patient safety literature review report. [Accessed January 5, 2006].

[12] Matney, S. a, Maddox, L. J. \& Staggers, N., (2014): Nurses as knowledge workers: is there evidence of knowledge in patient handoffs? Western journal of nursing research, 36(2), pp. 171-90.

[13] Maxson, P. M. et al., 2012. Promotes Patient Safety. MEDSURG NURSING, 21(3), pp. 140-145.

[14] Nelson, B. A., \& Massey, R. (2010): Implementing an Electronic Change-of-Shift Report of Clinical Nursing, 2010; 20, 184-189.

[15] Jefferies, D., Johnson, M. \& Nicholls, D., (2012): Comparing written and oral approaches to clinical reporting in nursing. Contemporary nurse, 42(1), pp. 129-38.

[16] Manser, T. \& Foster, S., (2011): Effective handover communication: an overview of research and improvement efforts. Best practice \& research. Clinical anesthesiology, 25(2), pp. 181-91. Available at:

http://www.ncbi.nlm.nih.gov/pubmed/21550543 [Accessed February 26, 2014.

[17] Elhanafy E., Hammour Z. (2014): Effect of educational sessions about effectiveness of handoff system for nurses on their knowledge and practice. The Egyptian Journal of Community Medicine. Vol. 32, No. 3, July 2014.

[18] Streeter, A. C. R. Kentucky, \& Harrington, N. G (2010): WHAT NURSES SAY: COMMUNICATION BEHAVIORS ASSOCIATED WITH THE COMPETENT NURSING HANDOFF. Published Doctorate Thesis. College of Communications and Information Studies at the University of Kentucky 16.

[19] Streeter, A. R., Harrington, N. G., \& Lane, D. R. (2015): Communication behaviors associated with the competent nursing handoff. Journal of Applied Communication Research, 43, 295-315.

[20] Angela G., Angela, R. L., Cathrin, C. \& Barbara, M. (2015): Integrating hand-off communication in to Undergraduate nursing clinical courses. Journal of Nursing Education and Practice, Vol. 5, No.4.

[21] Malekzadeh, j. Mazluom, s.r., Etezadi.t. \& Tasseri, a. (2013): A Standardized Shift Handover Protocol: Improving Nurses' Safe Practice in Intensive Care Units. Journal of Caring Sciences, 2(3), 177-185.

[22] Collins, S. a (2012): In search of common ground in handoff documentation in an intensive Care Unit. Journal of biomedical informatics, 45(2), pp.307-15.

[23] Jukkala, A. M. (2012): Developing a Standardized Tool to Improve Nurse Communication during Shift Report. Journal of Nursing Care Quality, 27(3), pp. 240-6. Available at: http://www.ncbi.nlm.nih.gov/pubmed/22437248 [Accessed February 17, 2014].

[24] Kesten KS. (2011): Role-play using SBAR Technique to Improve Observed Communication Skills in Senior Nursing Students. The Journal of Nursing Education. 1; 50(2):79-87. PMid: 21210611 http://dx.doi.org/10.3928/01484834-20101230-02.

[25] Carroll, J. S., M. Williams, and T. M. Gallivan. (2012). "The Ins and Outs of Change of Shift Handoffs between Nurses: a Communication Challenge." BMJ Quality \& Safety 21.7 (2012): 586-593.

[26] Halm, M. (2013). Nursing Handoffs: Ensuring Safe Passage for Patients. Ajccamerican Journal of Critical Care, March 2013, Volume 22, No. 2.

[27] Ewing, N. R. (2015): Best Practice for a Standardized and Safe Registered Nurse Shift Handoff. Submitted in Partial Fulfillment of the Requirements For the Degree of Doctor of Nursing Practice in Nursing College of Nursing University of South Carolina.

[28] Rowe, S., (2015). Improve Intra-Operative Nurse-To-Nurse Communication Using A Safety Checklist. Northern California Consortium, Doctor of Nursing Practice Program, California State University, Fresno and San José State University.

[29] Morsy M. (2014): The Effectiveness of Implementing Clinical Supervision Models on Head Nurses' Performance and Nurses' Job Satisfaction At Benha University Hospital. Faculty of Nursing, Benha University; 68p.

[30] Avallone, M. A. \& Weideman, Y. L. (2015): Evaluation of a nursing handoff educational bundle to improve nursing student handoff communication: A pilot study. Journal of Nursing Education and Practice. Vol. 5, No.8.

[31] Mekawy, H. S (2017): Impact of Implementing the Modified Electronic (ISOBAR) Nursing Handoff on Continuity of Care. Published Doctorate Thesis, Faculty of Nursing, Cairo University. p: 78,83.

[32] Perry, S. (2004): Transitions in Care: Studying safety in emergency department sign overs. Focus on Patient Safety, 7(2), 1-3. Retrieved June 9, 2005, from www.npsf.org.

[33] Rayo MF, Mount-Campbell AF, O' Brien JM, et al. (2014): Interactive questioning in critical care during handovers: a transcript analysis of communication behaviors by physicians, nurses and nurse practitioners. BMJ quality \& safety. 23(6): 483-9.

[34] Cohen MD, Hilligoss B, Kajdacsy-Balla Amaral AC. (2012): A handoff is not a telegram: an understanding of the patient is co-constructed. Critical Care. 16(1): 303. PMid:22316097 http://dx.doi.org/10.1186/cc10536

[35] Meloday, A. S. (2016): Impact of Nurses Fatigue and Nursing Handoff on Patient and Nurse Safety. Published Doctorate of Philosophy in Nursing. Department of Nursing. University of Texas. P: 61.

[36] Viverios, A. (2016): Nurses Perception of Electronic Handoff. Master Theses Dissertations, Graduate Research and Major Papers Overview. pp: 156. 